\title{
Parathyroid Autotransplantation during Thyroid Surgery
}

\author{
Ioannis Christakis, Vasilis A Constantinides, Neil S Tolley, Fausto F Palazzo
}

\begin{abstract}
Postoperative hypoparathyroidism is the commonest permanent complication of thyroid surgery. It results from the removal or devascularization of the parathyroid glands. Parathyroid autotransplantation is a tool to retain parathyroid function and to decrease the need for prolonged pharmacological support. The basis of the technique that we describe in detail is that described by Wells et al. Overall the success rates of immediate autotransplantation range between 85 and $99 \%$ and technique appears to play a key role.
\end{abstract}

Keywords: Parathyroid, Parathyroidectomy, Autotransplantation, Hypocalcemia, Thyroid surgery.

How to cite this article: Christakis I, Constantinides VA, Tolley NS, Palazzo FF. Parathyroid Autotransplantation during Thyroid Surgery. World J Endoc Surg 2012;4(3):115-117.

Source of support: Nil

Conflict of interest: None

\section{INTRODUCTION}

During all forms of neck surgery but in particular thyroid surgery the aim is to retain as much functional parathyroid tissue as possible. However, despite meticulous dissection adopting the well-described technique of capsular dissection some parathyroids are either removed or devascularized with inevitable loss of parathyroid function. ${ }^{1}$ Parathyroid autotransplantation is very useful tool in such circumstances to regain the parathyroid function essential for calcium homeostasis.

The autotransplantation of the parathyroid glands was first described in dogs by Halsted where he prevented the occurrence of tetany after total parathyroidectomy by reimplanting the excised parathyroid glands. ${ }^{2}$ The first applications of parathyroid autotransplantation in humans were given by Lahey and later Cattell amid skepticism around the importance of the technique. ${ }^{3-5}$ Interest was renewed when Sam Wells et al demonstrated graft survival rates of $93 \%$ in a series of 29 autotransplantations in man. ${ }^{6}$

Hypoparathyroidism is the commonest permanent complication of a total thyroidectomy. ${ }^{7-11}$ While the management of this problem with vitamin $\mathrm{D}$ analogs and oral calcium may in many patients be satisfactory, hypoparathyroidism can have considerable consequences on bone metabolism, renal function, the risk of cataract formation and quality of life. ${ }^{12-18}$

Parathyroid autotransplantation may be immediate and delayed. ${ }^{19}$ In immediate autotransplantation, the intraoperative implantation of a fresh parathyroid tissue into another location rather than delayed autotransplantation of cryopreserved tissue is the subject of this manuscript. The routine autotransplantation of at least one removed parathyroid gland can decrease the incidence of permanent hypoparathyroidism to less than $1 \% .^{1,20}$

The confirmation of the effectiveness of the parathyroid autotransplantation has sparked the appearance of several reports supporting the implementation of routine autotransplantation as an effective measure to minimize postoperative hypoparathyroidism. ${ }^{20,21}$ However, the removal of an undamaged gland appears to offer no reduction in the incidence of permanent post-thyroidectomy so a selective approach is usually preferred, in which mainly suspect, devascularized or inadvertently removed parathyroid glands are readily transplanted whenever, there is any concern. Equally autotransplantation may be preferred when a difficult and prolonged dissection of the pedicle is expected where the outcome is unlikely to be that of a healthy, functional parathyroid gland left in situ. ${ }^{1}$

\section{TECHNIQUE}

The basis of the technique employed in our department is loosely based on the technique described by Wells et al. ${ }^{22}$ After excision of the nonviable parathyroid gland it is then placed on a wet gauze or directly into a small pot containing balanced salt solution (BSS). The surgeon carefully inspects the removed gland to confirm the nature and exclude any evidence of gross pathology, such as macroscopic features of an adenoma or hyperplasia. In cases of doubt and to avoid reimplantation of malignant tissue during a thyroidectomy for malignancy a fragment of the gland can be submitted to frozen section examination to confirm the nature of the tissue to be autotransplanted. ${ }^{3}$ Parathyroid tissue should ideally be reimplanted as early after sacrifice as possible. Every effort should be made to avoid the desiccation that can occur under the intense theater illumination if not immediately placed in in BSS. The selected parathyroid gland is finely cut using fine scissors, such as Jamieson's scissors in $1.5 \mathrm{ml}$ of BSS to create the finest suspension possible (Fig. 1). The suspension of the minced parathyroid is then aspirated within a $2 \mathrm{ml}$ syringe. ${ }^{23,24}$ If all the tissue does not readily pass through the hub then the fragments are too thick and need further cutting. A Braun Micropin ${ }^{\circledR}$ needle is placed on the tip of the syringe and the transplanted sternocleidomastoid muscle to be injected is isolated. ${ }^{25-29}$ 
In frail patients with thin muscle care is taken to lift the muscle from the underlying internal jugular vein. A small amount of air is left in the syringe to make sure that the contents all end in the muscle rather than partly in the syringe barrel and the Micropin ${ }^{\circledR}$ is inserted into the sternomastoid muscle. ${ }^{29}$ The contents of the syringe are swiftly injected into the muscle belly taking care to avoid spillage (Fig. 2). The site of the muscle implantation can be marked with a nonabsorbable monofilament suture or with a metal clip for future reference although this is not necessary.

\section{RESULTS AND DISCUSSION}

The return of function of the transplanted parathyroid glands is variable ranging from weeks to 6 to 12 months. ${ }^{30,31}$ In this interval, depending on the number of parathyroids transplanted and the underlying medical condition the patient may require pharmacological support with synthetic vitamin D and calcium supplements if hypocalcemic. The

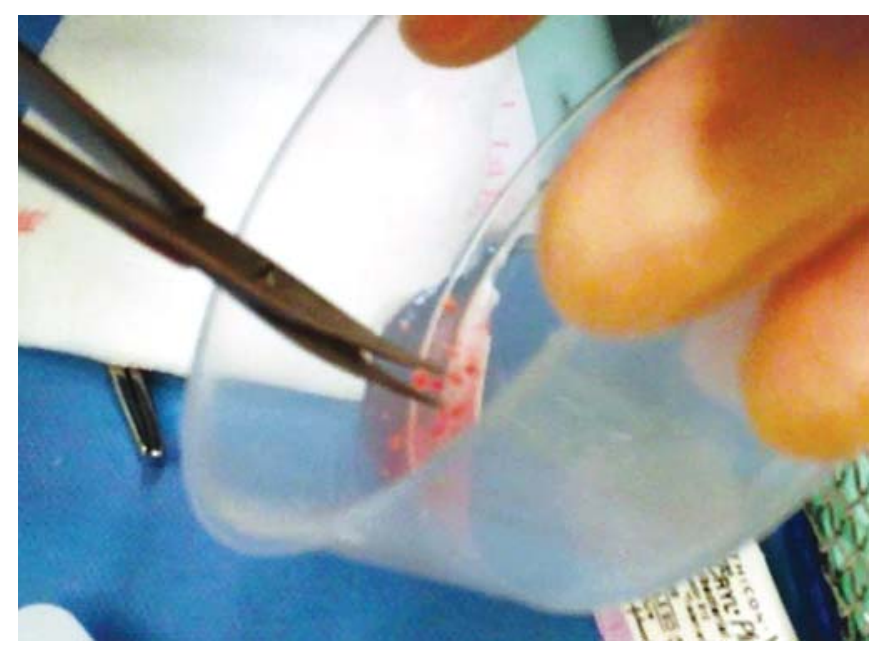

Fig. 1: Preparation of the parathyroid gland for autotransplantation

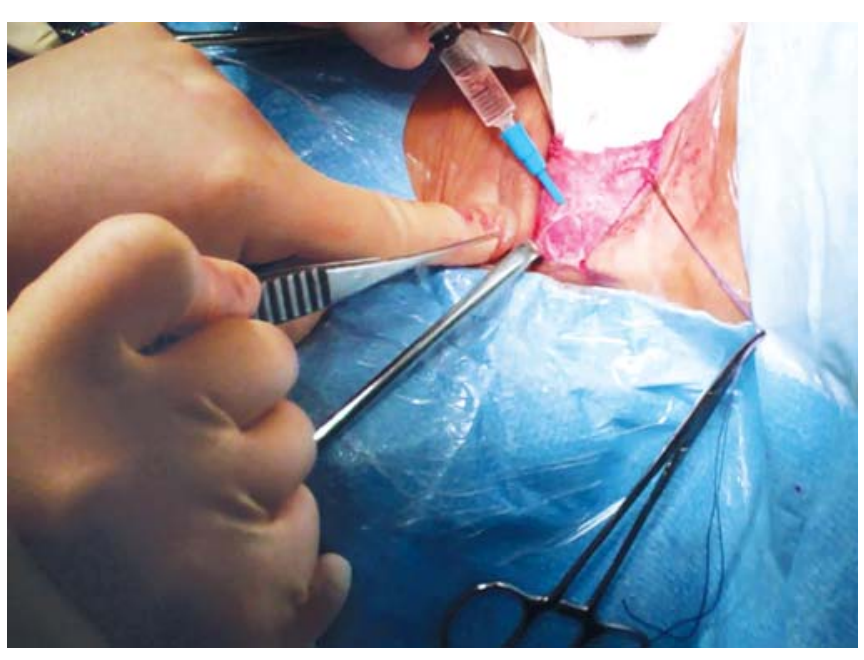

Fig. 2: Injection of the parathyroid solution to the sternocleidomastoid muscle outcome of a parathyroid autotransplantation is considered successful if the patient shows normal levels of serum calcium without the need for pharmacological support ideally within 6 months of surgery but usually much sooner. ${ }^{22,32}$ Overall success rates of immediate autotransplantation have been reported to reach levels between 85 and 99\%. ${ }^{33}$ However, determining whether it is the autotransplanted tissue or a preserved in situ or supernumerary parathyroid that is maintaining normocalcemia is a question that rarely can be resolved.

\section{REFERENCES}

1. Palazzo FF, et al. Parathyroid autotransplantation during total thyroidectomy - does the number of glands transplanted affect outcome? World J Surg 2005;29(5):629-31.

2. Halsted WS. Auto- and isotransplantation, in dogs, of the parathyroid glandules. J Exp Med 1909;11(1):175-99.

3. Lahey F. The transplantation of parathyroids in partial parathyroidectomy. Surg Gynecol Ohstet 1926;62:508.

4. Cattell R. Parathyroid transplantation. A report of autografts of parathyroid glands removed during thyroidcctomy. Am J Surg 1929;7:4-8.

5. Fisher B, et al. Thyroid and parathyroid implantation: An experimental reevaluation. Surgery 1967;62(6):1025-38.

6. Wells SA Jr, et al. Transplantation of the parathyroid glands in man: Clinical indications and results. Surgery 1975;78(1): 34-44.

7. Bhattacharyya N, Fried MP. Assessment of the morbidity and complications of total thyroidectomy. Arch Otolaryngol Head Neck Surg 2002;128(4):389-92.

8. British Association of Endocrine and Thyroid Surgeons, B (2012). Fourth National Audit Report. D Chadwick: 86.

9. Lindblom P, Westerdahl J, Bergenfelz A. Low parathyroid hormone levels after thyroid surgery: A feasible predictor of hypocalcemia. Surgery 2002;131(5):515-20.

10. Sahai A, Symes A, Jeddy T. Short-stay thyroid surgery. Br J Surg 2005;92(1):58-59.

11. McHenry CR, et al. Risk factors for postthyroidectomy hypocalcemia. Surgery 1994;116(4):641-47; discussion 647-48.

12. Arlt $\mathrm{W}$, et al. Well-being, mood and calcium homeostasis in patients with hypoparathyroidism receiving standard treatment with calcium and vitamin D. Eur J Endocrinol 2002;146(2): 215-22.

13. Huang QL. Clinical observations and calcium determinations in hypocalcemic cataract. Zhonghua Yan Ke Za Zhi 1989;25(5): 268-70.

14. Cusano NE, et al. Mini-review: New therapeutic options in hypoparathyroidism. Endocrine 2012;41(3):410-14.

15. Fotheringham J, et al. Post-parathyroidectomy parathyroid hormone levels: The impact on patient survival-a single-centre study in a stage 5 chronic kidney disease population. Nephron Clin Pract 2011;119(2):c113-20.

16. Ireland AW, et al. The crystalline lens in chronic surgical hypoparathyroidism. Arch Intern Med 1968;122(5):408-11.

17. Forman $\mathrm{MB}$, et al. Basal ganglia calcification in postoperative hypoparathyroidism. Clin Endocrinol (Oxf) 1980;12(4):385-90.

18. Goswami R, et al. Reversible peripheral neuropathy in idiopathic hypoparathyroidism. Acta Neurol Scand 2002; 105(2):128-31. 
19. Moffett JM, Suliburk J. Parathyroid autotransplantation. Endocr Pract 2011;17(Suppl 1):83-89.

20. Zedenius J, Wadstrom C, Delbridge L. Routine autotransplantation of at least one parathyroid gland during total thyroidectomy may reduce permanent hypoparathyroidism to zero. Aust NZ J Surg 1999;69(11):794-97.

21. Olson JA Jr, et al. Parathyroid autotransplantation during thyroidectomy. Results of long-term follow-up. Ann Surg 1996; 223(5):472-78; discussion 478-80.

22. Wells SA Jr, et al. Transplantation of the parathyroid glands: Current status. Surg Clin North Am 1979;59(1):167-77.

23. Tenta LT, Keyes GR. Transcervical parathyroidectomy with microsurgical autotransplantation and the viscerovertebral angle. Otolaryngol Clin North Am 1980;13(1):169-79.

24. Billings PJ, Milroy E. Autotransplantation of human parathyroid glands. Ann R Coll Surg Engl 1986;68(1):11-13.

25. Geis WP, et al. The diagnosis and treatment of hyperparathyroidism after renal homotransplantation. Surg Gynecol Obstet 1973;137(6):997-1010.

26. Esselstyn CB Jr, Levin HS. A technique for parathyroid surgery. Surg Clin North Am 1975;55(5):1047-63.

27. Salander H, Tisell LE. Latent hypoparathyroidism in patients with autotransplanted parathyroid glands. Am J Surg 1980; 139(3):385-88.

28. Paloyan E, et al. Total thyroidectomy and parathyroid autotransplantation for radiation-associated thyroid cancer. Surgery 1976;80(1):70-76.

29. Braun Medical, B(2012). Product Catalog B. Medical: A1.

30. Burnett HF, Thompson BW, Barbour GL. Parathyroid autotransplantation. Arch Surg 1977;112(4):373-79.

31. Mallette LE, Eisenberg K, Wilson H, Noon GP. Generalised primary parathyroid hyperplasia: Studies of the evolution of autogenous parathyroid graft function. Surgery 1983;93:254-59.
32. Edis AJ, Linos DA, Kao PC. Parathyroid autotransplantation at the time of reoperation for persistent hyperparathyroidism. Surgery 1980;88(4):588-93.

33. Feldman AL, et al. Results of heterotopic parathyroid autotransplantation: A 13-year experience. Surgery 1999;126(6):1042-48.

\section{ABOUT THE AUTHORS}

\section{loannis Christakis}

Specialist Registrar, Department of Thyroid and Endocrine Surgery Imperial College of Healthcare NHS Trust, Hammersmith Campus London, United Kingdom

\section{Vasilis A Constantinides}

Senior Registrar, Department of Thyroid and Endocrine Surgery Imperial College of Healthcare NHS Trust, Hammersmith Campus London, United Kingdom

\section{Neil S Tolley}

Consultant, Department of Thyroid and Endocrine Surgery, Imperial College of Healthcare NHS Trust, Hammersmith Campus, London United Kingdom

\section{Fausto F Palazzo (Corresponding Author)}

Consultant, Senior Lecturer, Department of Thyroid and Endocrine Surgery, Imperial College of Healthcare NHS Trust, Hammersmith Campus, Du Cane Road, London, United Kingdom, Phone: +442083838542, Fax: +4402083832037 e-mail: f.palazzo@imperialac.uk 